\title{
The political economy of skills and inequality
}

Rising socio-economic inequality is a common trend across advanced industrial democracies and its causes and consequences are still poorly understood. Certainly, the recent economic crisis has exacerbated the trend, in particular in countries most affected by the crisis, but the increase set in much earlier in the 1980s and even before. Furthermore, the trend cannot simply be explained by a return to markets because there has not been large-scale retrenchment of established welfare states.

A very prominent explanation in economics is that new technology shifts the demand away from low-skilled and towards high-educated workers, stretching the income distribution as a result. Yet, these shifts in the demand have to be compared with shifts in the supply of skills. In the influential 2010 book by Goldin and Katz on 'The Race between Education and Technology', they estimate this relationship empirically over long periods of time in the case of the USA. Their results are revealing. While the rate of skill-biased technological change after 1980 s was virtually identical to the previous two decades, the rise in the supply of college educated slowed markedly. Decelerating supply of skills, not accelerating demand, is therefore the main factor behind the rise in inequality. Goldin and Katz reject the notion that the USA has reached an upper limit for educational attainment, and they cite the success of other advanced democracies in expanding educational opportunities well beyond the levels in the USA. At the same time they do not offer a comparative analysis, and they stay strictly within the economic supplydemand framework that dominates the economic literature on inequality.

The purpose of this special issue is to move beyond and 'contextualize' this narrow economic perspective by bringing together cutting-edge research on the causes and consequences of inequality in the fields of comparative political economy and economic sociology. The contributions do so in several ways. First, they document differences in the rate of change in the supply of skills, and the effect these differences have on the wage distribution. This helps account for at least some of the cross-national variance in the rise of income inequality since the 1980s. Second, the contributions explain the role of socio-economic institutions, in particular skill formation and collective bargaining, influencing the quantity and quality of skill supply, as well as the demand for skilled workers. By doing so, 
they move 'behind' the supply-demand framework to consider the institutional context which shapes the level and composition of skills. Third, while institutions that affect demand and supply are implicitly treated as exogenous in the economic literature, the special issue contributions suggest in different ways how policymakers and organized interests can and do deliberately engage in institutional design in order to influence the supply of skills. Fourth, economic explanations fail to explain why governments do not compensate for rising inequality through more redistributive taxes and transfers. The special issue documents differences in the propensity of government to engage in such compensation and how this is related to national political institutions and partisan politics. Fifth and following from this, the economic framework does not have much to say about the longrun consequences of inequality on political power, and hence the possibilities for future spending and redistribution. In distinct ways, the contributions to this issue suggest why and how economic and political inequality may be mutually reinforcing. Finally, the papers for this special issue consider dimensions of inequality other than wages. Differences in wealth, in the exposure to labour market risks, in women's labour market opportunities compared with men's and in political influence are all important aspects of the emerging pattern of inequality since the 1980s.

There are eight contributions to this issue, and they can be broadly grouped in three clusters: the first explores the causes of rising in equality and asks how important education and skills are as determinants of this trend. The article by Huber and Stephens provides a broad overview over the most important determinants of socioeconomic inequality and how their explanatory power varies over time. The contribution by Solga focuses on the contemporary period, using a range of indicators measuring differences between education systems. Solga is particularly concerned with understanding the link between human capital and socio-economic inequality, which is less straightforward as often assumed.

The second set of papers focus on the critical role played by the education system in the political economy of inequality. The article by Busemeyer and Iversen is concerned with understanding a particular aspect of education financing: the division of labour between public and private sources of funding. The paper argues that electoral institutions and partisan coalitions shape this division with important, self-reinforcing implications for contemporary patterns of social inequality. Ansell and Gingrich look more closely at the case of the UK, highlighting the institutional and political connections between the housing market, sorting into good and bad schools and the consequences of such sorting for inequality. Wozny and Schneider analyse the impact of educational and vocational training institutions on the gender gap in further firm-based training. They find that the gender gap is larger in countries where vocational education and training is more important relative to academic higher education. 
The third set of papers zero in on the broader consequences and implications of socio-economic inequality on politics and political coalitions. Rueda looks at the association between labour market segmentation ('dualization') and the responsiveness of welfare states to economic crises. He finds that a high degree of dualization on the labour market delimits welfare state responsiveness, also during the recent economic and financial crisis. Rehm and Wren study the implications of the growing service economy and liberalization of trade in services on redistributive coalitions in the labour market. In particular, they take issue with a core claim of the compensation argument in globalization theories, showing that high-skilled workers in the exposed sectors of the economy are not more likely to demand social protection, and often support a leaner welfare state. Finally, Schneider and Makszin show that the institutional set-up of the welfare state and economy has implications for patterns of mass participation. Specifically, individuals in the lower half of the skills distribution are more likely to participate when they are protected by generous labour market policies.

In combination, the contributions to this special issue offer a window into leading-edge research on the complex relationship between skills and inequality. A theme running through many of the papers is that economic and political inequalities tend to be mutually reinforcing, which implies that cross-national differences are unlikely to disappear. Moreover, this insight exposes the danger of generalizing from a single case such as the American. Rather, this observation suggests the need for a political economy of inequality that is attentive to national institutional and political context, and how this context interacts with economic and sociological forces of change. The special issue aims to highlight the insights that can be gained from cross-disciplinary inquiry and dialogue, casting new light on economic, political and sociological determinants and their interactions. We hope the reader will find inspiration in these analyses and that they will spark debate and further research on the causes and consequences of inequality.

We would also like to take this opportunity to thank the authors and reviewers who contributed to this issue. Special thanks go to Gregory Jackson, the chief editor of Socio-Economic Review, and Sarah King, acting in the editorial office, for extraordinary support during the whole process. We also thank SASE for giving us the opportunity to discuss the papers during a mini-conference at the annual meeting in Milan in June 2013 as well as Evelyne Huber and John D. Stephens for hosting a second paper workshop at the University of North Carolina in Chapel Hill in November 2013.

Marius R. Busemeyer and Torben Iversen Guest Editors 